\title{
Article
}

\section{Dynamic Quality Monitoring System to Assess the Quality of Asphalt Concrete Pavement}

\author{
Ziyuan Ma ${ }^{1}{ }^{(\mathbb{D}}$, Jingxiao Zhang ${ }^{2, *}$, Simon P. Philbin ${ }^{3}{ }^{(D}$, Hui Li $^{4}$, Jie Yang ${ }^{5}$, Yunlong Feng ${ }^{5}$, \\ Pablo Ballesteros-Pérez ${ }^{6}(1)$ and Martin Skitmore ${ }^{7}$
}

Citation: Ma, Z.; Zhang, J.; Philbin, S.P.; Li, H.; Yang, J.; Feng, Y.;

Ballesteros-Pérez, P.; Skitmore, M. Dynamic Quality Monitoring System to Assess the Quality of Asphalt Concrete Pavement. Buildings 2021, 11, 577. https://doi.org/10.3390/ buildings 11120577

Academic Editor: Agnieszka Leśniak

Received: 19 October 2021

Accepted: 19 November 2021

Published: 24 November 2021

Publisher's Note: MDPI stays neutral with regard to jurisdictional claims in published maps and institutional affiliations.

Copyright: (c) 2021 by the authors. Licensee MDPI, Basel, Switzerland. This article is an open access article distributed under the terms and conditions of the Creative Commons Attribution (CC BY) license (https:// creativecommons.org/licenses/by/ $4.0 /)$.
1 School of Civil Engineering, Lanzhou Jiaotong University, Lanzhou 730070, China; maziyuan1020@126.com School of Economics and Management, Chang'an University, Xi'an 710064, China

3 Nathu Puri Institute for Engineering and Enterprise, School of Engineering, London South Bank University, London SE1 0AA, UK; philbins@1sbu.ac.uk

4 School of Civil Engineering, Chang'an University, Xi'an 710061, China; fdlu9002@126.com

5 China Road \& Bridge Corporation, Beijing 100027, China; yangj@crbc.com (J.Y.); fyunlong890917@gmail.com (Y.F.)

6 Departamento de Proyectos de Ingeniería, Universitat Politècnica de València, Camino de Vera $s / n$, 46022 Valencia, Spain; pabbalpe@dpi.upv.es

7 Faculty of Society \& Design, Bond University, Robina Q4229, Australia; mskitmor@bond.edu.au

* Correspondence: zhangjingxiao@chd.edu.cn

\begin{abstract}
With the rapid development of new technologies, such as big data, the Internet of Things (IoT) and intelligent sensing, the traditional asphalt pavement construction quality evaluation method has been unable to meet the needs of road digital construction. At the same time, the development of such technologies enables a new management system for asphalt pavement construction. In this study, firstly, the dynamic quality monitoring system of asphalt concrete pavement is established by adopting the BeiDou Navigation Satellite System, intelligent sensing, the IoT and 5G technology. This allows key technical indicators to be collected and transmitted for the whole process of asphalt mixture, which includes the mixing plant, transport vehicle, paving and compaction. Secondly, combined with AHP and the entropy weight (EW) method, the index combination weight is calculated. The comprehensive index for the pavement digital construction quality index (PCQ) is proposed to reflect the impact of monitoring indicators on pavement quality. An expert decision-making model is formed by using the improved particle swarm optimization (PSO) algorithm coupled with radial basis function neural network (RBF). Finally, the digital monitoring index and pavement performance index are connected to establish a full-time and multi-dimensional digital construction quality evaluation model. This study is verified by a database created from the digital monitoring data of pavement construction collected from a highway construction project. The system proposed in this study can accurately reflect the quality of pavement digital construction and solve the lag problem existing in the feedback of construction site.
\end{abstract}

Keywords: dynamic quality monitoring system; BeiDou Navigation Satellite System; information technology; construction quality management; RBF neural network; PSO optimization algorithm

\section{Introduction}

The construction of road transportation infrastructure continues to be a major sector across the world and pavement construction quality management has become an increasingly important issue to be addressed [1-3]. However, at present traditional asphalt pavement detection approach often adopts the manual recording method, which has obvious disadvantages, such as the potential for mistakes to be made and the difficulty in transferring the information digitally. In view of the lack of effective real-time supervision of certain key processes in the construction industry in conjunction with poor levels of digital technology adoption, it is difficult to detect and rectify quality problems in a timely 
fashion, which leads to the shortened service life of asphalt pavements [4-6]. Therefore, empirical research on digital construction quality management of asphalt pavement is of major significance in regard to the quality process control for pavement construction [7-9].

At present, many industrial sectors in China are accelerating the development of information technology as part of the process of digital transformation and this involves both digitization of data from manual recording to digital systems as well as digitalization of existing business processes into digital systems. For example, Sun [10] and others have applied the building information modeling (BIM) system to the quality management of construction engineering for the purpose of quality evaluation. Furthermore, Zhong [11] and others have applied Internet of Things (IoT) technology to the analysis of bridge construction management for information collection. The application of these information technologies has laid a foundation for the development of digital monitoring technology for asphalt pavement construction in highway engineering construction.

Adoption of digital monitoring technology for asphalt pavement construction can enable the realization of remote control tracking of the construction process. This has the potential to transform the previous manual inspection process into a digital process control system in order to enhance the efficient and effective quality control of highway construction projects. Indeed, Zhang [12] and others have developed an intelligent sensing aggregate (ISA) using advanced technologies, such as 3D printing and the Internet of Things. The system can collect and analyze data in real time, and the equipment also has resistance to high temperature. Hu [13] studied the use of an intelligent compactor to detect the compaction meter value (CMV) of pavement, and thereafter explored the relationship between CMV and asphalt pavement density. Moreover, Fares [14] used the intelligent asphalt compaction analyzer (IACA) to estimate the density during asphalt pavement construction so as to determine the quality of pavement compaction. It can therefore be observed that in existing research scholars have mainly focused on the use of digital monitoring equipment for the construction process of asphalt pavement. However, there appears to be a lack of research on the application of quality control tools for the whole process of pavement construction.

In order to make a more effective judgement on the construction quality of asphalt pavement, it is necessary to evaluate the different quality management systems. Zhang [15] proposed a pavement construction quality index system based on Internet of Things technology, which determined the weight of each index by AHP (analytic hierarchy process) and divided the comprehensive evaluation grade, whereas Hosseini [16] and others defined production and construction quality control indicators, and analyzed the relationship between pavement construction quality control indicators and pavement disease indicators. Zhou [17] established the data analysis system for asphalt pavement engineering quality process control by using the method of consistency checking, which realized the dynamic control of the asphalt pavement engineering quality process. Further, Zhang [18] introduced the percentage within limits method to quantify the quality of each index, and established the construction quality evaluation model for different layers of asphalt pavement by using AHP. While existing evaluation methods reflect the reliability and satisfaction of pavement construction quality, the key indicators for the pavement construction process monitored by information technology have not been fully considered. Consequently, an effective system that properly reflects the relationship between construction quality indicators and pavement performance still needs to be investigated and developed. Such an approach will improve the work efficiency of the constructor as well as for the owner and the supervisor, and thereby reduce the construction management costs.

The research study reported in this article aims to realize effective management of the whole process of asphalt pavement construction. In order to achieve this goal, the study adopted a range of technologies, namely the BeiDou satellite (BDS) navigation system combined with Internet of Things and intelligent sensing technology in order to develop the digital monitoring system for measuring asphalt pavement quality. The technology solution also uses a $5 \mathrm{G}$ wireless network to collect and transmit the key parameters collected 
of the main equipment in the asphalt pavement construction process. Through realtime and dynamic secondary mining of the collected parameters the data analysis and evaluation module was established. Based on this approach, this empirical study proposes the pavement digital construction quality index PCQ, and establishes the relationship model between the monitoring index and PCQ based on an IPSO-RBF neural network. The study verifies the effectiveness of the quality evaluation index through analyzing the quantitative correlation between PCQ and both the Pavement Condition Indicator (PCI) and International Roughness Index (IRI). This methodology offers a new way to enable quantitative evaluation of asphalt pavement quality.

\section{Development of the Dynamic Monitoring System for Asphalt Concrete Pavement Quality}

\subsection{Structure Design of Information Monitoring System}

The dynamic monitoring system for asphalt concrete pavement quality is composed of four subsystems, namely: Asphalt mixture production (1), transportation (2), paving (3) and rolling (4), which collectively integrates to form the whole process of asphalt mixture production and construction. The key parameters for the asphalt mixture mixing station, raw material transport vehicle, asphalt mixture paver and roller are extracted and collected through the Internet of Things, intelligent sensing and BDS systems. Compared with GPS, which can only accept location information, BDS can realize two-way communication and therefore offers significant benefits [19]. Table 1 provides details on the key monitoring contents of the digital monitoring system. The construction quality data is collected on site and is transmitted to the cloud data server in real time through 5G wireless network transmission technology for storage and management. Through real-time and dynamic analysis of the collected parameters, the system feeds back the abnormal data to the managers in the form of an SMS alarm [20,21]. The overall architecture for pavement construction quality digital monitoring system is shown in Figure 1.

\subsection{Composition of Digital Monitoring System}

\subsubsection{Communication Technology}

In highway construction projects and due to the discrete distribution of construction equipment, wired broadband networks cannot meet the requisite needs of mobile machinery on the construction site. Therefore, with the aim of ensuring the timeliness and accuracy of monitoring data, the dynamic monitoring system of asphalt concrete pavement quality adopts the 5G (3GPP) wireless communication network system to collect and transmit data. As a new generation of communication technology, the $5 \mathrm{G}$ communication network shows obvious advantages in transmission rate, coverage and low delay [22-24]. Indeed, the transmission rate of the $5 \mathrm{G}$ network can reach $10 \mathrm{Gbit} / \mathrm{s}$, which greatly improves the data transmission rate. At the same time, the communication delay can be reduced to approximately $1 \mathrm{~ms}$, which effectively solves the problem of data transmission delay $[25,26]$.

\subsubsection{Quality Control System for Asphalt Mixture Mixing}

The quality control system for the asphalt mixture mixing process includes the data acquisition module, $5 \mathrm{G}$ network transmission module and data processing module to realize the dynamic monitoring of raw materials in the mixing station. The data-collection system of the mixing plant is constructed by installing an SBW series temperature transmitter (SBWR4560, Shanghai Automation Instrumentation CO., LTD, Shanghai, China) next to the discharge bin and METTLER - TOLEDOIND series load cells (SPC, METTLER TOLEDO, Shanghai, China) in the screening system of the reduction bin. This enables collection of the aggregate consumption, asphalt consumption, mixture mixing temperature and discharge temperature in real time, and calculates the asphalt aggregate ration and grading of each plate. The collected data is transmitted to the remote central server through the industrial control computer in the control room of the mixing plant (as shown in Figure 2). The data 
processing module of the system can provide a professional data analysis table and mixture grading curve to construction engineering and project managers.

\subsubsection{Quality Control System for Asphalt Mixture Transportation}

The quality control system for asphalt mixture transportation is composed of vehicle positioning, temperature collection, on-board video monitoring and intercom subsystems. Based on the BDS system [27-29], the positioning module is installed on asphalt concrete transportation vehicles, which can collect transportation vehicle information, driver information, transportation track and transportation speed. Additionally, radio-frequency identification (RFID) technology is used to install labels and readers on the truck, mixing station and paving site to collect the start and end transportation time in order to calculate the transportation cycle parameters [30-33]. The temperature of the asphalt mixture during asphalt concrete transportation is monitored in real time by the temperature sensor. Figure 3 shows the system architecture for the real-time monitoring system for asphalt mixture transportation.

Table 1. Main monitoring indicators of digital monitoring system.

\begin{tabular}{cc}
\hline Main Construction Machinery & Monitoring Indicators \\
\hline Mixing plant & $\begin{array}{c}\text { Asphalt aggregate ration, grading, asphalt weight, } \\
\text { mixture temperature, mixing time, silo weightand } \\
\text { discharge temperature. }\end{array}$ \\
\hline Transport vehicle & $\begin{array}{c}\text { Loading time, loading place, transportation route, } \\
\text { transportation time and transportation speed. }\end{array}$ \\
\hline Paver & $\begin{array}{c}\text { Paving track, paving speed, paving time and } \\
\text { asphalt temperature. }\end{array}$ \\
\hline Roller & $\begin{array}{c}\text { Rolling speed, rolling track, rolling times, asphalt } \\
\text { temperature and vibration frequency. }\end{array}$ \\
\hline
\end{tabular}

\subsubsection{Quality Control System for Asphalt Concrete Pavement Paving}

The quality control system for asphalt concrete pavement paving is composed of screed real-time tracking and positioning, integrated controller, 5G wireless communication network and temperature acquisition systems. Based on the BDS system and carrier phase splitting real-time kinematic (RTK) technique [34-37], coordinate information data transmission is carried out by installing reference stations and mobile stations on the construction site and construction machines and tools, respectively, so as to obtain the paving track, paving speed and paving time. In addition, multi-point infrared thermal imaging equipment is installed on the paver to acquire the overall pavement temperature of the asphalt mixture to monitor the paving temperature and pavement uniformity $[38,39]$. At the same time, the system display terminal LED screen enables operators to obtain visual paving information and thereby helps guide construction operations. The digitized asphalt pavement paver is shown in Figure 4.

\subsubsection{Quality Control System for Asphalt Concrete Pavement Rolling}

The main equipment for the asphalt mixture rolling quality control system includes mobile station, temperature sensor and vibration sensor. The subsystem is based on RTK technology. According to setting the reference station and vehicle mobile station, the centimeter level positioning of the roller is achieved by using differential positioning and triangle positioning principles. This enables a continuous collection of data on rolling times, rolling speed and travel direction. The system's positioning accuracy is $1-3 \mathrm{~cm}$ in the horizontal direction and $2-5 \mathrm{~cm}$ in the vertical direction. The infrared temperature sensor and acceleration sensor are used to collect the rolling temperature, roller vibration frequency and compaction meter value data. The data are transmitted to the remote central server in real time through TCP/IP protocol. Using the visual operating system in the cab 
of the roller, the rolling information is sent to the vehicle touch screen controller of the display and control terminal to feed back the rolling state information of asphalt mixture in real time. This approach helps to guide equipment operators to achieve the expected compaction state. The digitized asphalt pavement roller is shown in Figure 4.

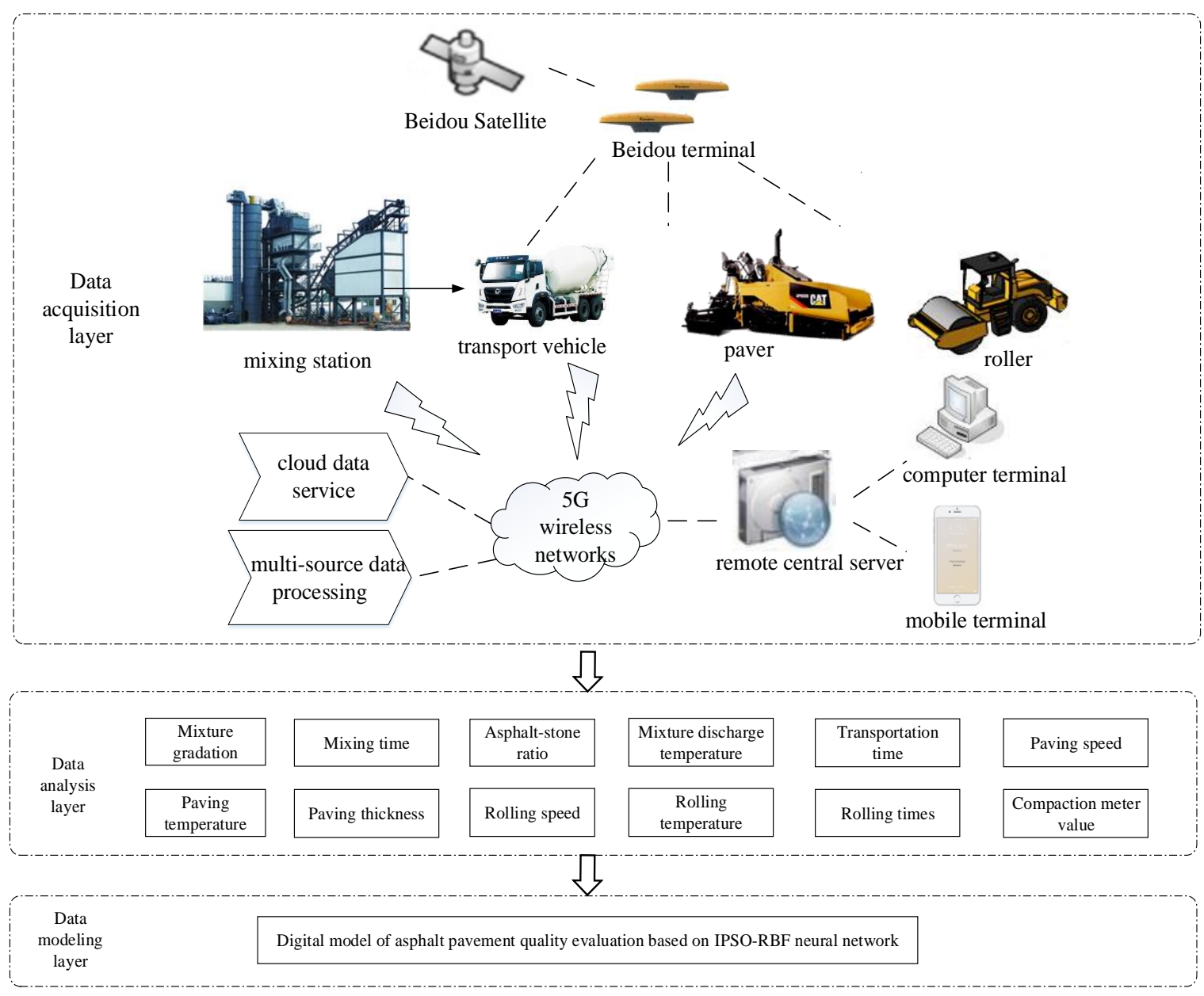

Figure 1. Structure diagram of the digital monitoring system for measuring asphalt pavement construction quality.

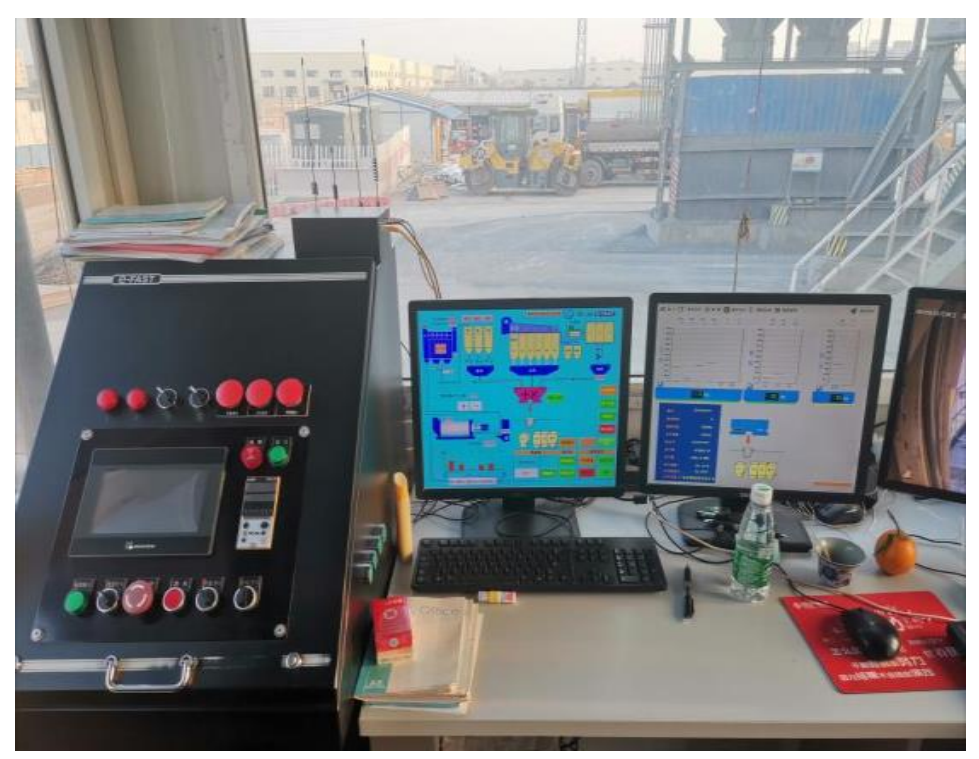

Figure 2. Data acquisition equipment in control room of mixing plant. 


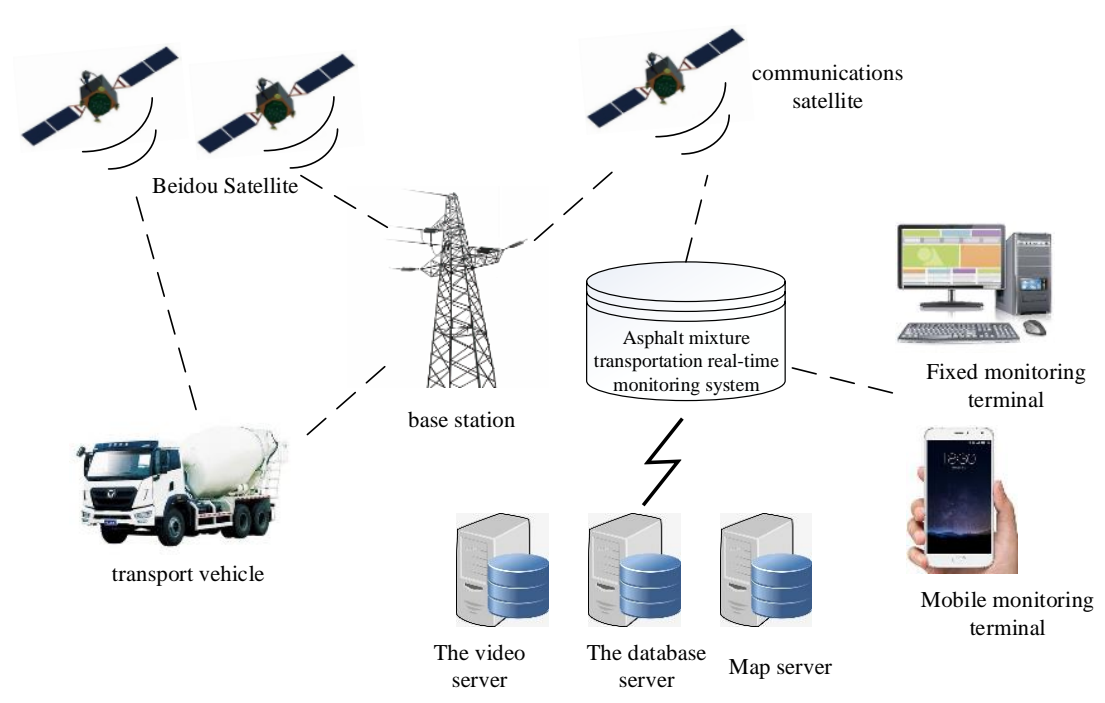

Figure 3. System architecture of the asphalt mixture transportation monitoring system.

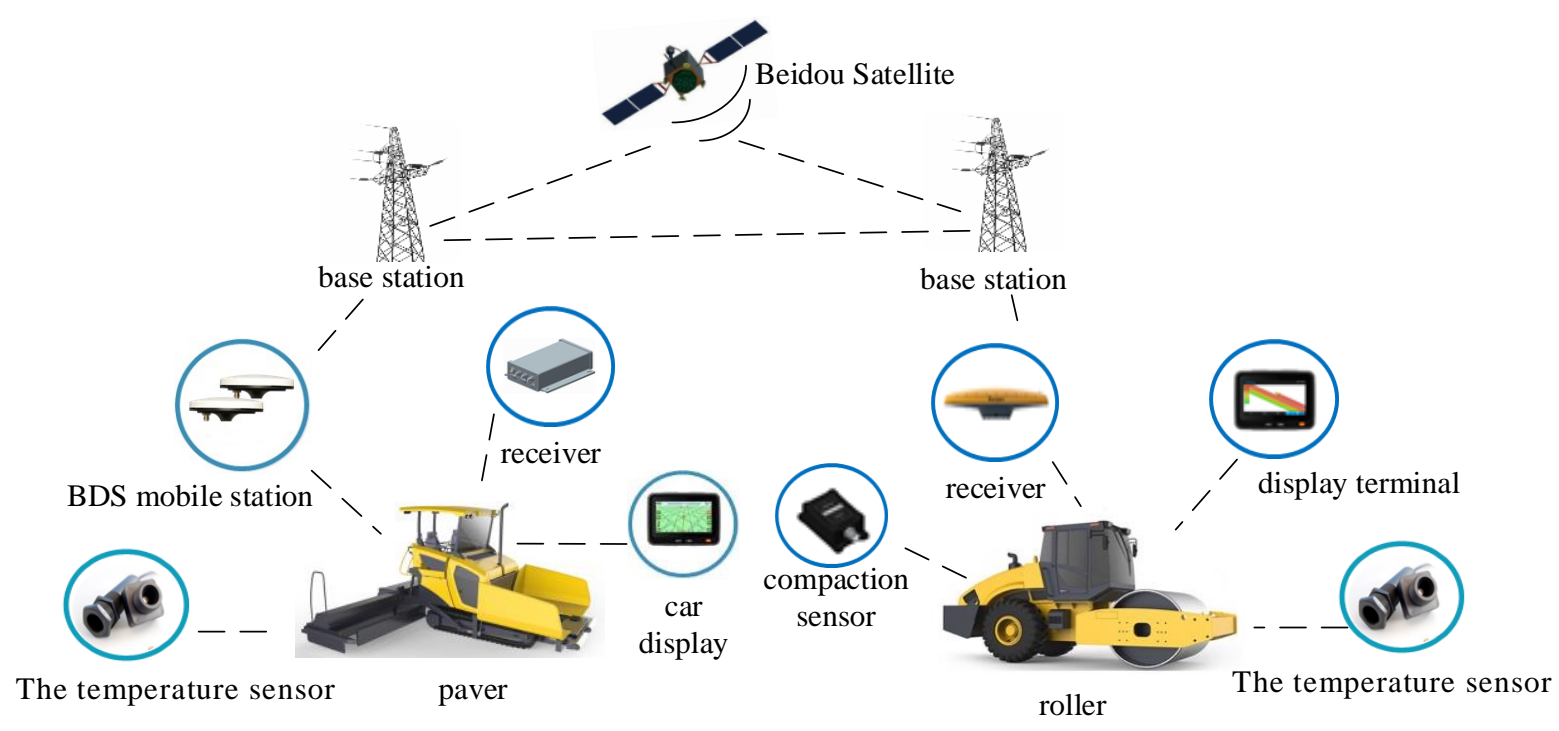

Figure 4. Asphalt pavement paver and roller after digital transformation.

\section{Coupling Model Based on Multidimensional Data Source and Asphalt Pavement Construction Quality}

3.1. Digital Construction Quality Evaluation Index System for Asphalt Pavement

The dynamic monitoring system for asphalt concrete pavement quality allows the key control parameters of each link in the process of asphalt mixture production and construction to be accurately obtained. This provides an accurate data source for the thorough assessment of pavement digital construction quality. On this basis and through depth analysis of the critical technical indicators in the process of pavement digital construction, a quantifiable evaluation index system for the construction quality of digital asphalt pavement is established. This is in accordance with the principle of easy detection and this approach also reflects the final pavement quality [40-42]. The specific evaluation index system is shown in Figure 5.

In this empirical research study, the pavement digital construction quality index (PCQ) is introduced to accurately represent the quality of asphalt pavement. The comprehensive evaluation index PCQ is calculated according to Formula (1).

$$
P C Q=\sum_{i=1}^{12} \omega_{i} P_{i}
$$

where $w_{i}$ and $P_{i}$ are the weight and index value of each index, respectively. 


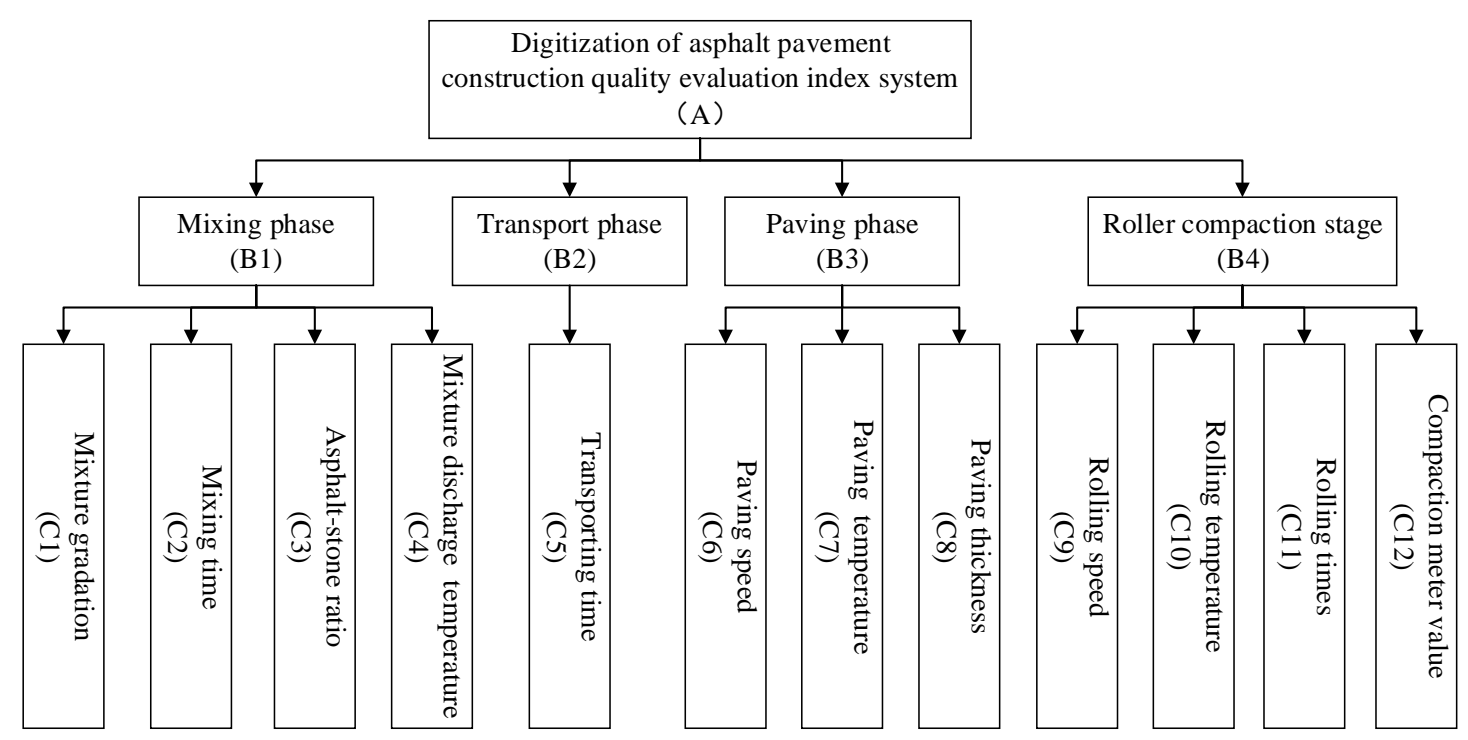

Figure 5. Digital construction quality evaluation index system of asphalt pavement.

\subsection{Selection of the Evaluation Method for Asphalt Pavement Construction Quality}

3.2.1. Selection of Quality Measurement Methods

At present, the pass rate method is usually adopted as the measurement method for pavement quality but this method cannot fully consider the data distribution and overall trend. Compared with the pass rate method, the percentage within the allowable limit (PWL) method comprehensively considers the mean and standard deviation of the sample data $[43,44]$, which can effectively reflect the fluctuation of the monitoring data.

The calculation result of PWL reflects the percentage of the sample meeting the limit requirements, which is used as the quality score of each sub-index of the pavement. Therefore, this study uses the PWL method to quantify pavement quality to ensure the rationality of evaluation results [45]. The final score of the PWL is calculated according to Formulas (2)-(4).

$$
\begin{aligned}
Q_{M} & =\frac{T_{M}-\bar{x}}{S} \\
Q_{L} & =\frac{\bar{x}-T_{L}}{S}
\end{aligned}
$$

where $Q_{M}$ and $Q_{L}$ are the quality index of upper limit and lower limit of the allowable limit, respectively; $T_{M}$ and $T_{L}$ are the allowable upper and lower limit of corresponding parameters, respectively; $\bar{x}$ and $S$ are the mean value and standard deviation of parameter samples of each road section.

The PWL table can be queried according to the sample number $n$ to obtain $P W L_{w}$ and $P W L_{L}$ values, and according to the Formula (4) to calculate the final $P W L$ value.

$$
P W L=P W L_{W}+P W L_{L}-100
$$

where $P W L_{w}$ and $P W L_{L}$ are the percentage within the allowable limit corresponding to $Q_{M}$ and $Q_{L}$, respectively.

\subsubsection{Determination of Weight of Asphalt Pavement Construction Quality} Evaluation Index

This study uses the method of combining subjective and objective perspectives to calculate the comprehensive weight of the index.

(1) Subjective weighting method based on AHP

According to the evaluation index system shown in Figure 5, the method is divided into three levels, namely: Target level, criterion level and scheme level. Combined with expert opinions, the judgement matrix $A$ is established by using the 1-9 scale method. The 
feature vector $W$ corresponding to the maximum eigenvalue $\lambda_{\max }$ of the judgment matrix is calculated and normalized as the objective weight vector $w^{\prime}=\left(w_{1}^{\prime}, w_{2}^{\prime}, \ldots, w_{n}^{\prime}\right)^{T}$ of the index [46-48].

$$
A=\left(a_{i j}\right)_{n \times n}=\left[\begin{array}{cccc}
a_{11} & a_{11} & \ldots & a_{11} \\
a_{21} & a_{21} & \ldots & a_{21} \\
\ldots & \ldots & \ldots & \ldots \\
a_{n 1} & a_{n 2} & \ldots & a_{n n}
\end{array}\right]
$$

where $a_{i j}$ is the importance of index $i$ over index $j$, and $a_{i j}=\frac{1}{a_{j i}}$.

In order to verify the rationality of the judgement matrix, it is essential to calculate the consistency index $C I$ and consistency ratio $C R$ according to Formulas (6) and (7). The consistency of the judgment matrix requires $C R<0.1$, and the weight is valid.

$$
\begin{gathered}
C I=\frac{\lambda_{\max }-n}{n-1} \\
C R=\frac{C I}{R I}
\end{gathered}
$$

(2) Objective weighting method based on EW

The entropy weight method uses entropy to reflect the uncertainty of information [49-51]. The information content of the index is inversely proportional to the entropy. There are $m$ samples and $N$ evaluation indexes. The initial decision matrix is $X=\left(x_{i j}\right)_{m \times n}$. After standardization, the decision matrix $R=\left(r_{i j}\right)_{m \times n}$ is obtained.

$$
\begin{aligned}
X & =\left[\begin{array}{cccc}
x_{11} & x_{12} & \ldots & x_{1 n} \\
x_{21} & x_{22} & \ldots & x_{2 n} \\
\ldots & \ldots & \ldots & \ldots \\
x_{m 1} & x_{m 2} & \ldots & x_{m n}
\end{array}\right] \\
R & =\left[\begin{array}{cccc}
r_{11} & r_{12} & \ldots & r_{1 n} \\
r_{21} & r_{22} & \ldots & r_{2 n} \\
\ldots & \ldots & \ldots & \ldots \\
r_{m 1} & r_{m 2} & \ldots & r_{m n}
\end{array}\right]
\end{aligned}
$$

According to Formula (10), the entropy of item $\mathrm{j}$ is calculated:

$$
E_{j}=-\frac{1}{\ln (n)} \sum_{i=1}^{m} r_{i j} \ln r_{i j}
$$

According to Formula (11), the objective weight of indexes are calculated:

$$
\omega^{\prime \prime}=\frac{1-E_{j}}{k-\sum_{k=1}^{n} E_{k}}
$$

(3) Subjective and objective coupling weight

The combination weight of the index is determined by coupling AHP with the EW method, which cannot only take account of the experience of experts, but also must effectively avoid subjectivity of weight. This is to reasonably evaluate the pavement quality and thereby more accurately reflect the actual situation of the pavement [52]. Therefore, the combination weight $w_{i}$ of subjective and objective factors is calculated according to Formula (12).

$$
\omega_{i}=\frac{\sqrt{\omega_{i}^{\prime} \omega_{i}^{\prime \prime}}}{\sum_{i=1}^{n} \sqrt{\omega_{i}^{\prime} \omega_{i}^{\prime \prime}}}\left(0 \leq \omega_{i} \leq 1, \sum_{i=1}^{n} \omega_{i}=1\right)
$$

where $w_{\mathrm{i}}{ }^{\prime}$ and $w_{\mathrm{i}}{ }^{\prime \prime}$ are the subjective weight and the objective weight, respectively. 


\section{Digital Construction Quality Evaluation Model for Asphalt Pavement Based on IPSO-RBF}

\subsection{Establishment of Evaluation Model Based on RBF Neural Network}

The RBF neural network is a feedforward neural network [53-55] and it is composed of the input layer, hidden layer and output layer [56,57]. RBF is an ideal calculation tool for nonlinear problems (see Figure 6 for details on the RBF structure). The specific calculation process is defined by $\mathrm{Wu}$ [58]. In this study, the PWL score of each index of pavement digital construction quality evaluation is used as the input layer. Further, the pavement digital construction quality index PCQ calculated by combined weight is used as the output layer. At the same time, the samples are classified into the training set and test set. Through iterative training, the model training parameters are continuously optimized according to the mean square error (MSE).

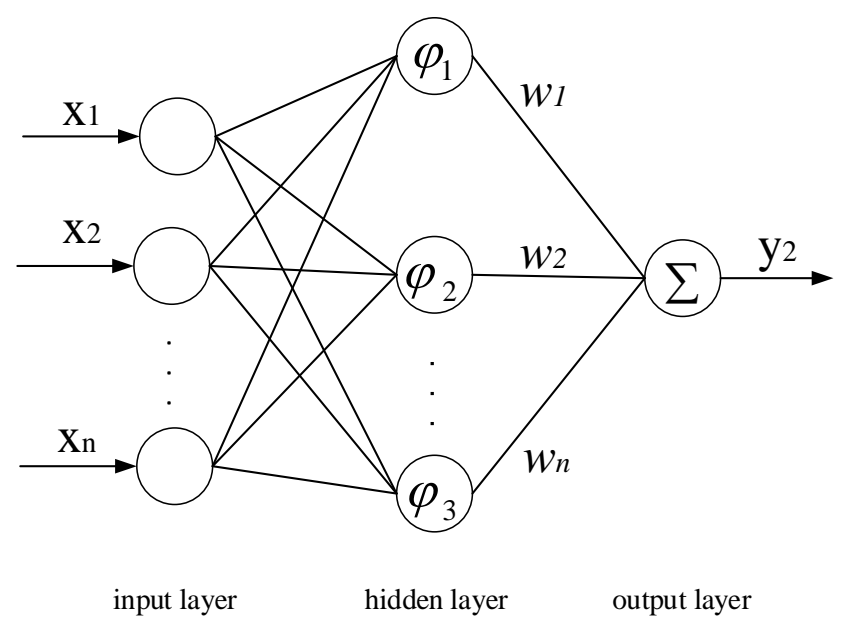

Figure 6. Radical basic function neural network model structure.

\subsection{Expert Decision Model of IPSO Algorithm}

PSO is an optimization algorithm based on prediction of bird behavior [59]. Compared with other optimization algorithms, the PSO algorithm is more prominent in optimization efficiency and stability [60]. Each particle represents a feasible solution of the problem to be optimized, and has two attributes of speed and position, which are expressed by Formulas (13) and (14), respectively [61-63]. In the iterative optimization process, the particle obtains the optimal solution satisfying the conditions by constantly updating the optimal positions of individuals and groups.

$$
\begin{gathered}
v_{i}^{k+1}=\omega^{k} v_{i}^{k}+c_{1} r_{1}\left(\text { pbest }_{i}-x_{i}^{k}\right)+c_{2} r_{2}\left(\text { gbest }_{i}-x_{i}^{k}\right) \\
x_{i}^{k+1}=x_{i}^{k}+v_{i}^{k+1}
\end{gathered}
$$

where $v_{i d}^{k}$ and $x_{i d}^{k}$ is the velocity and position of particle $i$ at the $k$-th iteration, respectively. Moreover, pbest and gbest are the optimal location of individuals and groups, respectively. $c_{1}$ and $c_{2}$ are learning factors, which adjust the maximum learning step. $r_{1}$ and $r_{2}$ are two random numbers with a value range of $[0,1] . w$ is the inertia weight factor.

In the algorithm, the inertia weight factor is usually set as a constant [64]. When calculated in this way, the particle cannot vary the inertia weight according to the current position in the optimization process, and cannot balance the local and global optimization ability of the particle [65]. Therefore, this study improves the inertia weight factor to optimize the PSO algorithm. The improved inertia weight calculation formula is provided in Formula (15). This approach adopts the nonlinear decreasing method, that is, the inertia weight decreases rapidly at the initial stage of iteration, which can effectively avoid the particles falling into the local poor area. With the increase of iteration times, the inertia weight decreases slowly, which enables the particles to accurately find the optimal position near the optimal solution. 


$$
\omega=\omega_{\max }-\left(\omega_{\max }-\omega_{\min }\right)\left(1-e^{-\frac{2 k}{k_{\max }}}\right)
$$

where $w_{\max }$ and $w_{\min }$ are the initial and final weight values, respectively. $k$ is the current number of iterations; $k_{\max }$ is the maximum number of iterations.

\subsection{Decision Model of Pavement Quality Evaluation Based on IPSO-RBF}

With the aim of improving the efficiency and exactitude of the neural network algorithm, this study proposes a RBF network decision-making model based on an improved PSO algorithm. The PSO algorithm is utilized to train three key parameters of the RBF neural network, namely: The center value, width and output weight of hidden layer. Figure 7 provides the flow chart for the road digital construction quality evaluation model based on an IPSO-RBF neural network. The specific prediction steps are as follows:

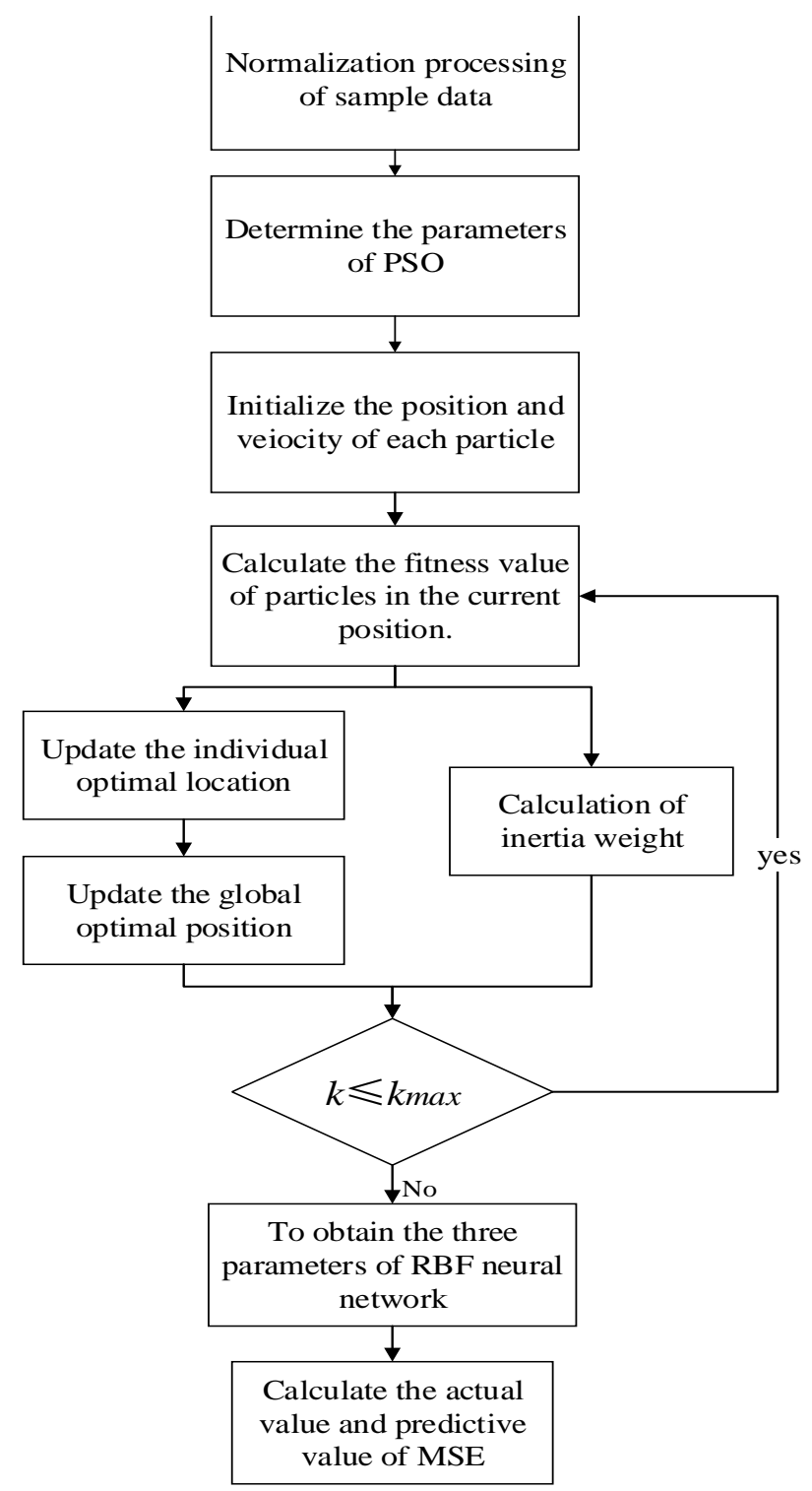

Figure 7. Flow chart of digital construction quality evaluation model for asphalt pavement based on IPSO-RBF.

Step 1. Initialize sample data. The data are normalized, and the sample data are divided into the test set and training set.

Step 2. Determine relative parameters of the PSO algorithm. This includes the number of particles, the maximum number of iterations and the initialization position and speed of particles. 
Step 3. Identify the number of hidden layer nodes in the RBF neural network by the trial-and-error method on the basis of Formula (16). At the same time, combined with the pavement digital construction quality evaluation index system, the number of nodes of input layer and output layer are determined.

$$
a=\frac{n_{r}+n_{c}}{2} \leq n_{y} \leq\left(n_{r}+n_{c}\right)+10=b
$$

where $n_{r}, n_{c}$ and $n_{y}$ are the number of input layers, output layers and hidden layer nodes of RBF neural network, respectively.

Step 4. Optimize the relative parameters of the RBF neural network. The centre, width and the output weight of the hidden layer are used as particle information in search of the preferred parameter combination in the iterative process.

Step 5. Calculate the fitness value of the current position of the particle. The MSE between the predicted value and the actual value is used as the fitness function, as shown in Formula (17). This approach can judge whether to update the optimal position of the current particle and the optimal position of the population particles in accordance with the fitness value of the current position.

$$
\text { fitness }=\frac{1}{n} \sum_{i=1}^{n}\left(y_{i}^{\prime}-y_{i}\right)^{2}
$$

where $n$ is the number of samples. $y_{\mathrm{i}}{ }^{\prime}$ and $y_{i}$ are the prediction value and actual value of the particle, respectively.

Step 6. Renew the velocity and position information of particles according to Formulas (13) and (14). When the number of iterations exceeds the set maximum number of iterations, step 7 is performed; otherwise step 5 is reverted in order to repeat the iterative processes. Step 7. Calculate the MSE between the predicted value and the actual value of the pavement quality evaluation decision model based on IPSO-RBF to assess the exactness of the model.

\section{Example Verification and Model Training}

\subsection{Application Case Study}

With the aim of verifying the applicability of the digital construction quality evaluation model for asphalt pavement, this study adopts a digital highway construction project as an illustrative example to evaluate construction quality. In this project, firstly, based on the dynamic monitoring system of asphalt concrete pavement quality established above, the construction quality monitoring equipment is installed on one asphalt mixing plant, 20 asphalt mixture transportation vehicles, five pavers and 10 rollers involved in the project, so as to realize the digital transformation of construction machinery. Secondly, advanced technologies, such as BDS, 5G and the Internet of Things, are used to collect the evaluation index data of the asphalt mixture production, transportation, paving and rolling on the construction site. At the same time, the digital quality evaluation model of asphalt pavement established in this study is used to evaluate the pavement quality. Thirdly, the PCQ proposed in this study is combined with the pavement performance index to verify the effectiveness of the model.

To enable scientific evaluation of the quality of pavement digital construction, 20 industry experts were invited to form an expert group, which included project construction participants, company managers and researchers in pavement construction. The 1-9 scaling method was used to score the index. The judgement matrix of the target layer and the criterion layer was established from bottom to top according to the hierarchical structure of the evaluation index system, and the consistency test was carried out according to Formulas (6) and (7). The score of the evaluation index system is shown in Table 2, and the subjective weight of the final index is shown in Table 3. The initial matrix is established according to the PWL score value of each evaluation index, and the objective weights shown in Table 4 were obtained by using the entropy weight method calculation Formulas (10) and (11). Finally, the subjective and objective combination weights were obtained according to Formula (12). The value of each index combination weight is shown in Table 5. 
Table 2. Judgement matrix of indicator layer A and indicator layer B.

\begin{tabular}{|c|c|c|c|c|c|}
\hline A & B1 & B2 & B3 & B4 & $w_{i}$ \\
\hline B1 & 1 & 3 & 2 & 1 & 0.3584 \\
\hline B2 & $1 / 3$ & 1 & $1 / 2$ & $1 / 3$ & 0.1100 \\
\hline B3 & $1 / 2$ & 2 & 1 & 1 & 0.2301 \\
\hline B4 & 1 & 3 & 1 & 1 & 0.3015 \\
\hline B1 & $\mathrm{C} 1$ & $\mathrm{C} 2$ & C3 & $\mathrm{C} 4$ & $w_{i}$ \\
\hline $\mathrm{C} 1$ & 1 & 2 & 1 & 1 & 0.2810 \\
\hline $\mathrm{C} 2$ & $1 / 2$ & 1 & 1 & $1 / 3$ & 0.1571 \\
\hline C3 & 1 & 1 & 1 & 1 & 0.2428 \\
\hline $\mathrm{C} 4$ & 1 & 3 & 1 & 1 & 0.3191 \\
\hline B3 & C6 & C7 & \multicolumn{2}{|c|}{$\mathrm{C} 8$} & $w_{i}$ \\
\hline C6 & 1 & 1 & \multicolumn{2}{|c|}{2} & 0.4126 \\
\hline C7 & 1 & 1 & \multicolumn{2}{|c|}{1} & 0.3275 \\
\hline $\mathrm{C} 8$ & $1 / 2$ & 1 & \multicolumn{2}{|c|}{1} & 0.2599 \\
\hline B4 & C9 & C10 & C11 & C12 & $w_{i}$ \\
\hline C9 & 1 & 1 & $1 / 2$ & $1 / 2$ & 0.1692 \\
\hline C10 & 1 & 1 & $1 / 2$ & 1 & 0.2046 \\
\hline C11 & 2 & 2 & 1 & 1 & 0.3383 \\
\hline C12 & 2 & 1 & 1 & 1 & 0.2879 \\
\hline
\end{tabular}

Table 3. Calculation results of subjective weight $\left(w_{i}{ }^{\prime}\right)$ of AHP.

\begin{tabular}{cccccc}
\hline Indexes & $\boldsymbol{w}_{\boldsymbol{i}}{ }^{\prime}$ & Indexes & $\boldsymbol{w}_{\boldsymbol{i}}{ }^{\prime}$ & Indexes & $\boldsymbol{w}_{\boldsymbol{i}}{ }^{\prime}$ \\
\hline $\mathrm{C} 1$ & 0.1008 & $\mathrm{C} 5$ & 0.1100 & $\mathrm{C} 9$ & 0.0510 \\
$\mathrm{C} 2$ & 0.0576 & $\mathrm{C} 6$ & 0.0943 & $\mathrm{C} 10$ & 0.0600 \\
$\mathrm{C} 3$ & 0.0864 & $\mathrm{C} 7$ & 0.0759 & $\mathrm{C} 11$ & 0.1020 \\
$\mathrm{C} 4$ & 0.1152 & $\mathrm{C} 8$ & 0.0598 & $\mathrm{C} 12$ & 0.0870 \\
\hline
\end{tabular}

Table 4. Calculation results of objective weight $\left(w_{i}{ }^{\prime \prime}\right)$ by the entropy weight method.

\begin{tabular}{cccccc}
\hline Indexes & $\boldsymbol{E} \boldsymbol{j}$ & $\boldsymbol{w}_{\boldsymbol{i}}{ }^{\prime \prime}$ & Indexes & $\boldsymbol{E} \boldsymbol{j}$ & $\boldsymbol{w}_{\boldsymbol{i}}{ }^{\prime \prime}$ \\
\hline C1 & 0.9819 & 0.0486 & $\mathrm{C} 7$ & 0.9839 & 0.0432 \\
$\mathrm{C} 2$ & 0.9751 & 0.0668 & $\mathrm{C} 8$ & 0.9674 & 0.0874 \\
C3 & 0.9646 & 0.0948 & $\mathrm{C} 9$ & 0.9848 & 0.0408 \\
C4 & 0.9677 & 0.0865 & $\mathrm{C} 10$ & 0.9681 & 0.0855 \\
C5 & 0.9705 & 0.0792 & $\mathrm{C} 11$ & 0.9355 & 0.1731 \\
C6 & 0.9645 & 0.0952 & $\mathrm{C} 12$ & 0.9631 & 0.0989 \\
\hline
\end{tabular}

Table 5. Combination weight of AHP and EW.

\begin{tabular}{cccccc}
\hline Indexes & $\boldsymbol{w}_{\boldsymbol{i}}$ & Indexes & $\boldsymbol{w}_{\boldsymbol{i}}$ & Indexes & $\boldsymbol{w}_{\boldsymbol{i}}$ \\
\hline $\mathrm{C} 1$ & 0.0712 & $\mathrm{C} 8$ & 0.0950 & $\mathrm{C} 9$ & 0.0464 \\
$\mathrm{C} 2$ & 0.0631 & $\mathrm{C} 7$ & 0.0964 & $\mathrm{C} 10$ & 0.0729 \\
$\mathrm{C} 3$ & 0.0921 & $\mathrm{C} 6$ & 0.0583 & $\mathrm{C} 11$ & 0.1352 \\
$\mathrm{C} 4$ & 0.1061 & $\mathrm{C} 5$ & 0.0736 & $\mathrm{C} 12$ & 0.094 \\
\hline
\end{tabular}

\subsection{Model Training and Simulation Results}

On the basis of the actual construction situation of the highway project, a continuous $1 \mathrm{~km}$ section is defined as an evaluation section. A total of 30 sections are selected from the database as data samples, including 20 sets of data as training samples and 10 sets of data as test samples. The PWL score is calculated by querying the PWL table according to the actual data value of each index. The samples are trained by MATLAB 2016a software (The MathWorks, Inc., Natick, MA, USA). The PWL values of 12 evaluation indexes are 
used as the input layer and the comprehensive index PCQ is used as the output layer. The relevant parameter settings of the PSO algorithm are shown in Table 6. The final model parameters are determined by comparing the MSE. Using the trial-and-error method, when the number of hidden layers of RBF neural network is 5, the precision of the model is high. Meanwhile, the constant inertia weight PSO-RBF neural network model is used as the comparison model, where $w=0.6$, and the other parameters adopt the same value. The MSE and R2 calculations for the two models are shown in Table 7. The simulation results of the training set and test set are shown in Figure 8a,b, respectively.

Table 6. Parameters of the PSO model.

\begin{tabular}{cc}
\hline Parameter & Value \\
\hline$n$ & 200 \\
$k_{\max }$ & 300 \\
$w_{\min }$ & 0.4 \\
$w_{\max }$ & 0.9 \\
$c_{1}$ & 1.8 \\
$c_{2}$ & 1.8 \\
\hline
\end{tabular}

Table 7. The comparative result between the two models.

\begin{tabular}{ccc}
\hline Model Type & MSE & R2 \\
\hline PSO-RBF & 0.0796 & 0.9202 \\
IPSO-RBF & 0.0613 & 0.9475 \\
\hline
\end{tabular}

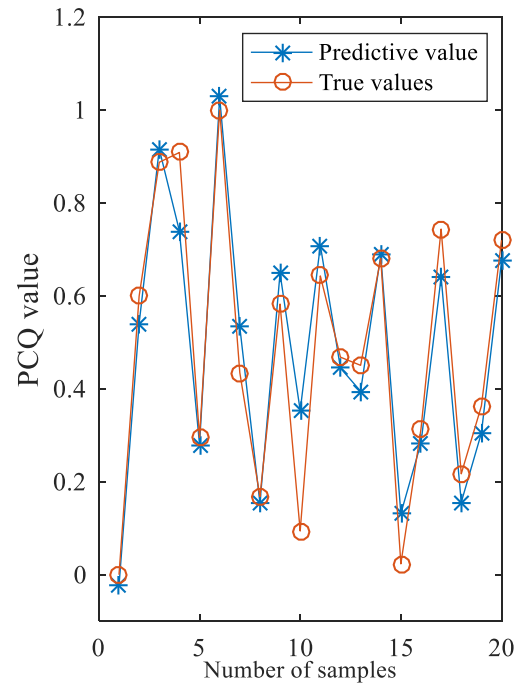

(a)

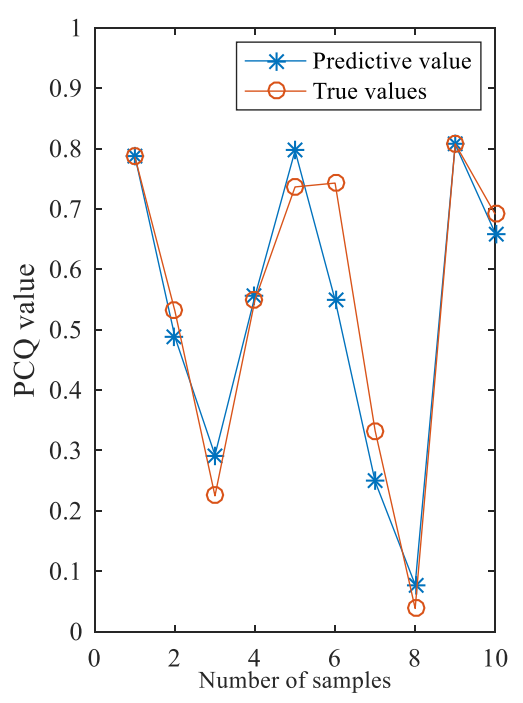

(b)

Figure 8. (a) Simulation results of the digital construction quality evaluation model of training set. (b) Simulation results of the digital construction quality evaluation model of test set.

In comparison with the traditional PSO-RBF training model, it can be observed that the improved model is closer to the actual situation and the error is smaller. Therefore, it is feasible to use the IPSO-RBF model to evaluate pavement construction quality. Furthermore, when evaluating the construction quality of asphalt pavement for similar pavement, the corresponding evaluation index data can be substituted into the trained IPSO-RBF model and the corresponding PCQ value can be obtained during the construction process. Consequently, this approach can transform the post-quality inspection into in-process quality inspection, which allows the unqualified sections to be ascertained in a timely manner. 
5.3. Correlation Analysis between the Comprehensive Evaluation Index of Pavement Construction Quality and Pavement Performance

With the purpose of verifying the validity of the PCQ index proposed in this study, the pavement condition index (PCI) and international roughness index (IRI) of the above 30 sections after construction are investigated and collected. According to this approach the PCI index is detected by use of a comprehensive road inspection vehicle and the IRI index is measured by the continuous flatness meter method. The linear correlation analysis between PCQ and with both PCI and IRI is carried out by using IBM SPSS Statistics 26 software (International Business Machines Corporation, Armonk, NY, USA). The validity of the PCQ comprehensive evaluation index is verified by connecting multi-source data and the analysis results are shown in Figures 9 and 10.

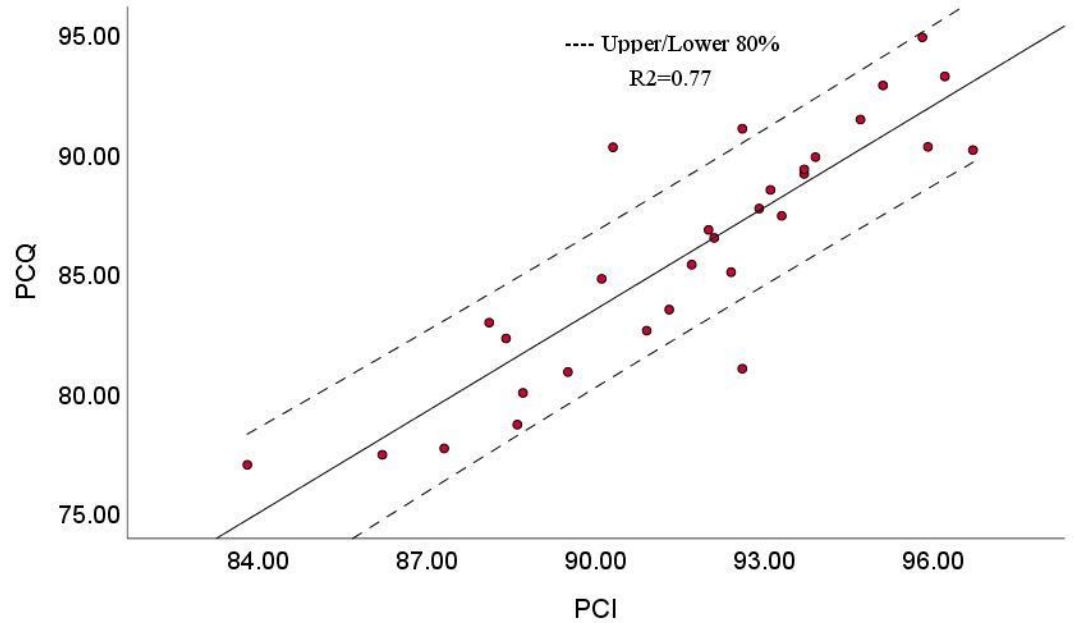

Figure 9. Correlation analysis between PCQ and PCI.

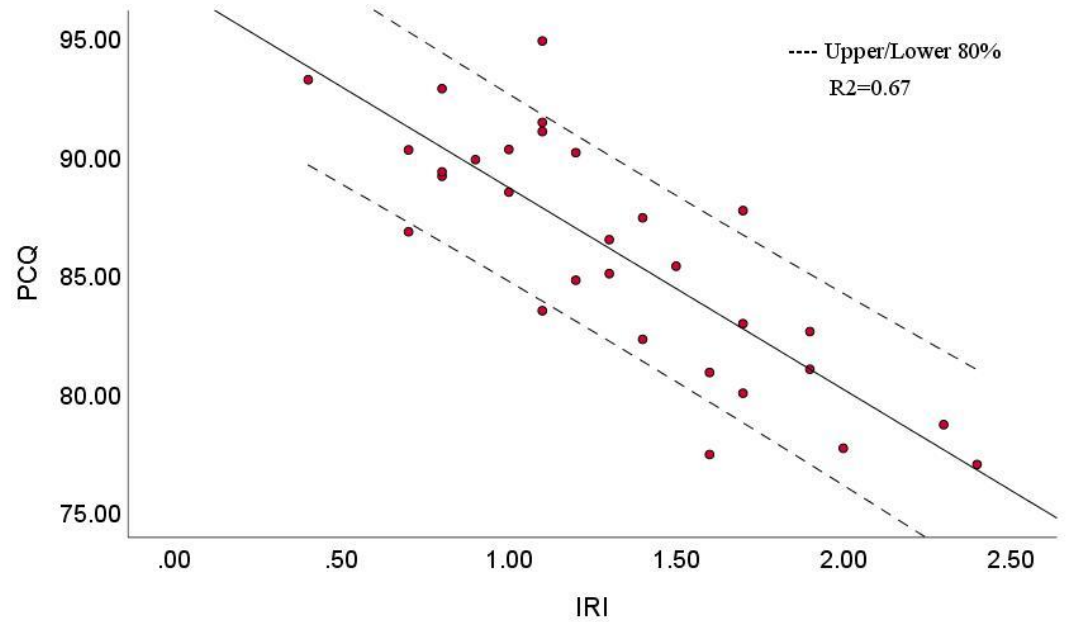

Figure 10. Correlation analysis between PCQ and IRI.

Figure 9 highlights that with the increase of PCI, PCQ gradually increases, thereby demonstrating a positive correlation. From Figure 10 it can be observed that as IRI increases, PCQ gradually decreases, thereby demonstrating a negative correlation. Indeed, PCI has a strong correlation with PCQ and IRI, which is consistent with the actual construction of pavement. Therefore, PCQ represents an effective method to evaluate the construction quality of asphalt pavement.

\section{Discussion}

In order to enable the digital transformation and improved quality management of pavement construction, this study has developed a dynamic quality monitoring system for 
asphalt concrete pavement based on the BDS system in conjunction with other new digital technologies. The system implementation covers the whole process of asphalt mixture production, transportation, on-site paving and rolling, which provides a new method for asphalt pavement digital construction. Internet of Things, 5G and GNSS technologies have been applied to all key aspects of asphalt pavement construction. This approach realizes the digital management of pavement construction combined with the timeliness and traceability of quality evaluation data. Compared with the traditional monitoring method, the new system solves the problem of lag of monitoring data of pavement construction, so that measures can be identified and pursued to solve the possible pavement construction quality problems in a timely fashion.

At the same time and through advancing our understanding of research on digital construction quality evaluation of asphalt pavement, this study further discusses the key influencing factors of digital construction quality evaluation as the object of digital acquisition, transmission and analysis of the asphalt pavement construction process, and establishes a complete digital monitoring system for pavement construction. Moreover, a decision model of asphalt pavement quality evaluation based on the IPSO-RBF neural network is established to further investigate the relationship between monitoring parameters and pavement performance, and a new quantitative index PCQ is proposed. In this study, 30 road sections are selected for road construction quality evaluation. The illustrative example shows that PCQ can accurately reflect the pavement quality, and the IPSO-RBF neural network model can be deployed to evaluate pavement quality quickly and precisely, which underscores the application of this research study in the asphalt pavement construction sector.

In this empirical study the relationship between performance indexes after completion of pavement construction with the comprehensive evaluation index PCQ of pavement construction (involving asphalt mixture production, transportation, paving and rolling) has only been explored preliminarily and consequently the process requires further development. Therefore, it is essential to further study the relevance between PCQ and the performance indicators of pavement use and the maintenance stage to calculate and determine the controlling index range of PCQ. Such an approach will need to establish the evaluation criteria for PCQ indicators with probabilistic curves created by the data collected so that the model achieves more robust generalization.

Author Contributions: Conceptualization, Z.M. and J.Z.; Methodology, Z.M.; Software, J.Z. and H.L.; Validation, S.P.P. and J.Z.; Formal Analysis, P.B.-P. and M.S.; Investigation, J.Y. and Y.F.; Resources, Z.M., P.B.-P. and M.S.; Data Curation, J.Y. and Y.F.; Writing-Original Draft Preparation, Z.M. and H.L.; Writing-Review \& Editing, Z.M., J.Z and S.P.P.; Visualization, S.P.P.; Supervision, J.Z.; Project Administration, J.Z. All authors have read and agreed to the published version of the manuscript.

Funding: This research is supported by the Branch of China Road and Bridge Corporation (Cambodia) Technology Development Project(No.2020-zlkj-04); National Social Science Fund projects (No.20BJY010); National Social Science Fund Post-financing projects (No.19FJYB017); Sichuan-tibet Railway Major Fundamental Science Problems Special Fund (No.71942006); Qinghai Natural Science Foundation (No.2020-JY-736); List of Key Science and Technology Projects in China's Transportation Industry in 2018-International Science and Technology Cooperation Project (No.2018-GH-006 and No.2019-MS5-100); Emerging Engineering Education Research and Practice Project of Ministry of Education of China (No.E-GKRWJC20202914); Shaanxi Social Science Fund (No.2017S004); Xi'an Construction Science and Technology Planning Project (No.SZJJ201915 and No.SZJJ201916); Shaanxi Province Higher Education Teaching Reform Project (No.19BZ016); Fundamental Research for Funds for the Central Universities (Humanities and Social Sciences), Chang'an University (No.300102239616, No.300102281669 and No.300102231641).

Institutional Review Board Statement: Not applicable.

Informed Consent Statement: Not applicable.

Data Availability Statement: The data presented in this study are available on request from the corresponding author. 
Conflicts of Interest: The authors declare no conflict of interest.

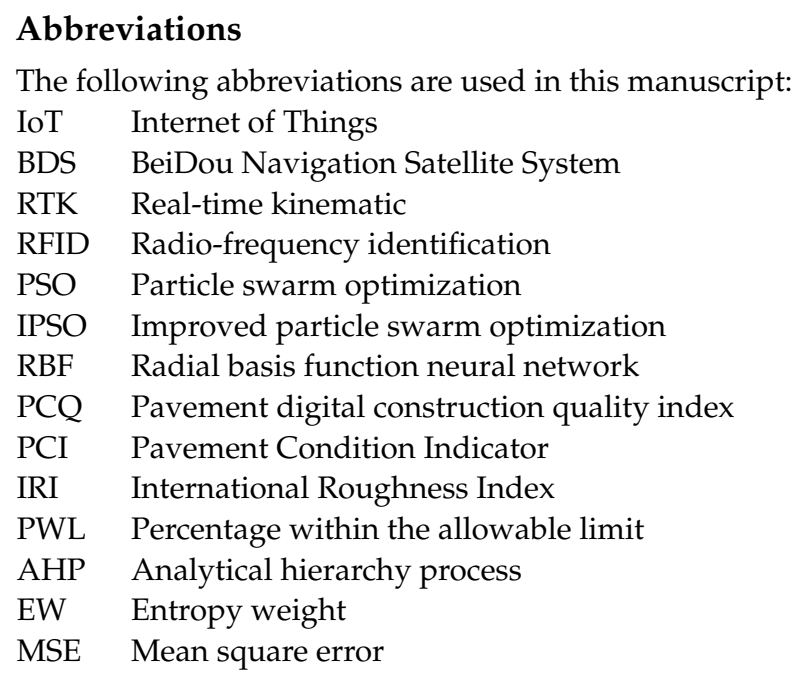

\section{References}

1. Hoxha, E.; Vignisdottir, H.; Barbieri, D.; Wang, F.; Bohne, R.; Kristensen, T.; Passer, A. Life cycle assessment of roads: Exploring research trends and harmonization challenges. Sci. Total Environ. 2021, 759, 143506. [CrossRef]

2. Zhang, J.-X.; Li, H. Optimization design on dynamic characteristics and fatigue life of automotive suspension system. J. Vibroeng. 2015, 17, 2547-2558.

3. Liu, Y.; Qian, Z.; Hu, H.; Shi, X.; Chen, L. Developing a skid resistance prediction model for newly built pavement: Application to a case study of steel bridge deck pavement. Road Mater. Pavement Des. 2021, 22, 1-19. [CrossRef]

4. Guo, D. Application of Pavement Quality Indicator in the Construction Quality Instant Control of Asphalt Pavement. In Proceedings of the 2nd International Conference on Measurement, Instrumentation and Automation (ICMIA 2013), Guilin, China, 23-24 April 2013; pp. 1691-1694.

5. Zhihao, Y. Research on Asphalt Pavement Diseases and Construction Quality Control under the Background of Big Data. J. Phys. Conf. Ser. 2021, 1744, 042139.

6. Petkevicius, E.; Petkevicius, R.; Babickas, R. Investigation of asphalt concrete pavement quality of Lithuanian highways. Balt. J. Road Bridge Eng. 2006, 1, 71-76.

7. Fandong, K.; Kaidi, L.; Cheng, C.; Xiaoyu, D.; Huanjing, J. Application of digital construction whole process monitoring and management technology for airport asphalt pavement. IOP Conf. Ser. Earth Environ. Sci. 2021, 643, 012190.

8. Zhang, X.; Zhang, R.; Liu, Y.; Xia, F.; Li, G. Airfield area operation digital management system based on 3-D GIS. J. Nanjing Univ. Aeronaut. Astronaut. 2016, 48, 761-771.

9. Amrani, M.; Taha, Y.; Kchikach, A.; Benzaazoua, M.; Hakkou, R. Phosphogypsum recycling: New horizons for a more sustainable road material application. J. Build. Eng. 2020, 30, 101267. [CrossRef]

10. Sun, H.; Wang, L.; Yang, Z.; Xie, J. Research on Construction Engineering Quality Management Based on Building Information Model and Computer Big Data Mining. Arab. J. Sci. Eng. 2021. [CrossRef]

11. Zhong, K.; Ma, F. Analysis of Intelligent Bridge Construction Management Guided by Building Information Model +Digitization +Internet of Tings Technology. Highway 2021, 66, 203-208.

12. Zhang, C.; Zheng, Y. Study on the Evaluation Standard of Construction Quality for Asphalt Pavement Based on the Intelligent Sensing Aggregate. Adv. Civ. Eng. 2021, 2021, 9985627. [CrossRef]

13. Hu, W.; Huang, B.; Shu, X.; Woods, M. Utilising intelligent compaction meter values to evaluate construction quality of asphalt pavement layers. Road Mater. Pavement Des. 2017, 18, 980-991. [CrossRef]

14. Beainy, F.; Commuri, S.; Zaman, M. Quality Assurance of Hot Mix Asphalt Pavements Using the Intelligent Asphalt Compaction Analyzer. J. Constr. Eng. Manag. Asce 2012, 138, 178-187. [CrossRef]

15. Lili, Z.; Jianping, H.; Shuai, W. Comprehensive Evaluation Method for Asphalt Pavement Construction Quality Based on Internet of Things Technology. In Proceedings of the 2021 IEEE Asia-Pacific Conference on Image Processing, Electronics and Computers (IPEC), Dalian, China, 14-16 April 2021; pp. 11-15.

16. Hosseini, A.; Faheem, A.; Titi, H.; Schwandt, S. Evaluation of the long-term performance of flexible pavements with respect to production and construction quality control indicators. Constr. Build. Mater. 2020, 230, 116998. [CrossRef]

17. Zhou, W.; Guo, D.; Li, X. Research on Process Control of Asphalt Pavement Construction Quality Based on Consistency Checking Method. J. Highw. Transp. Res. Dev. 2011, 28, 31-35.

18. Zhang, Y.; Li, L. Asphalt Pavement Construction Quality Evaluation Model and Weight Calculation Based on Analytic Hierarchy Process. J. Tongji Univ. (Nat. Sci.) 2011, 39, 253-258. 
19. Pan, L.; Li, X.; Yu, W.; Dai, W.; Kuang, C.; Chen, J.; Chen, F.; Xia, P. Performance Evaluation of Real-Time Precise Point Positioning with Both BDS-3 and BDS-2 Observations. Sensors 2020, 20, 6027. [CrossRef]

20. Seiffert, H.L.D.L.; Balbo, J.T. Development and validation of an ultrasound imaging software for nondestructive evaluation of concrete pavements. Rev. IBRACON Estrut. Mater. 2021, 14, e14511. [CrossRef]

21. Tello-Cifuentes, L.; Aguirre-Sánchez, M.; Díaz-Paz, J.P.; Hernández, F. Evaluación de daños en pavimento flexible usando fotogrametría terrestre y redes neuronales. TecnoLógicas 2021, 24, 59-71. [CrossRef]

22. Chen, S.-Z.; Kang, S.-L. A tutorial on 5G and the progress in China. Front. Inf. Technol. Electron. Eng. 2018, 19, 309-321. [CrossRef]

23. Yu, H.; Lee, H.; Jeon, H. What is 5G? Emerging 5G Mobile Services and Network Requirements. Sustainability 2017, 9 , 1848. [CrossRef]

24. Bin Zikria, Y.; Kim, S.W.; Afzal, M.K.; Wang, H.; Rehmani, M.H. 5G Mobile Services and Scenarios: Challenges and Solutions. Sustainability 2018, 10, 3626. [CrossRef]

25. Huo, Y.; Dong, X.; Xu, W.; Yuen, M. IEEE In Cellular and WiFi Co-design for 5G User Equipment. In Proceedings of the IEEE 5G World Forum (5GWF), Santa Clara, CA, USA, 9-11 July 2018; pp. 256-261.

26. Saily, M.; Barjau, C.; Navratil, D.; Prasad, A.; Gomez-Barquero, D.; Tesema, F.B. 5G Radio Access Networks: Enabling Efficient Point-to-Multipoint Transmissions. IEEE Veh. Technol. Mag. 2019, 14, 29-37. [CrossRef]

27. Ge, Y.; Ding, S.; Qin, W.; Zhou, F.; Yang, X.; Wang, S. Performance of ionospheric-free PPP time transfer models with BDS-3 quad-frequency observations. Measurement 2020, 160, 107836. [CrossRef]

28. Fang, X.; Fan, L. Accuracy analysis of BDS-2/BDS-3standard point positioning. Gnss World China 2020, 45, 19-25.

29. Shi, C.; Wu, X.; Zheng, F.; Wang, X.; Wang, J. Modeling of BDS-2/BDS-3 single-frequency PPP with B1I and B1C signals and positioning performance analysis. Measurement 2021, 178, 109355. [CrossRef]

30. Grover, A.; Berghel, H. A Survey of RFID Deployment and Security Issues. J. Inf. Process. Syst. 2011, 7, 561-580. [CrossRef]

31. Zhang, L.-H.; Li, T.; Fan, T.-J. Radio-frequency identification (RFID) adoption with inventory misplacement under retail competition. Eur. J. Oper. Res. 2018, 270, 1028-1043. [CrossRef]

32. Zhou, S.-J.; Zhang, W.-Q.; Luo, J.-Q. Survey of privacy of radio frequency identification technology. J. Softw. 2015, 26, 960-976.

33. Farris, I.; Iera, A.; Spinella, S.C. Introducing a Novel "Virtual Communication Channel" into RFID Ecosystems for IoT. IEEE Commun. Lett. 2013, 17, 1532-1535. [CrossRef]

34. Pan, Z.; Chai, H.; Dong, B.; Liu, M.; Wang, H. Real-time GPS Precise Satellite Clock Error Estimation and Precise Point Positioning. Hydrogr. Surv. Charting 2015, 35, 12-15.

35. Shi, J.; Yuan, X.; Cai, Y.; Wang, G. GPS real-time precise point positioning for aerial triangulation. GPS Solut. 2017, $21,405-414$. [CrossRef]

36. Chen, L.; Geng, C.; Zhou, Q. Estimation Model and Accuracy Analysis of BeiDou /GPS Real-time Precise Satellite Clock Error Integrated Resolving. Acta Geod. Cartogr. Sin. 2016, 45, 1028-1034.

37. Shi, J.; Ouyang, C.; Peng, W.; Huang, Y.; Xu, C. A Simplified BDS Broadcast Ephemeris and State Space Representative (SSR) Matching Method for BDS-Only Real-Time Precise Point Positioning (PPP). IEEE Access 2019, 7, 125205-125213. [CrossRef]

38. Zhang, K.; Sun, P.; Li, L.; Zhao, Y.; Zhao, Y.; Zhang, Z. A novel evaluation method of aggregate distribution homogeneity for asphalt pavement based on the characteristics of texture structure. Constr. Build. Mater. 2021, 306, 124927. [CrossRef]

39. Yang, Y.; Wang, H.; Yang, Y.; Zhang, H. Evaluation of the evolution of the structure of cold recycled mixture subjected to wheel tracking using digital image processing. Constr. Build. Mater. 2021, 304, 124680. [CrossRef]

40. Butkevicius, S.; Petkevicius, K.; Kamaitis, I.Z. Evaluation of flexible road pavement construction state using objective strength criteria. Balt. J. Road Bridge Eng. 2007, 2, 61-66.

41. Zhang, Z.-Q.; Xu, Y.-H.; Hu, H.-S.; Shi, W.; Zhang, K. Digital Image Evaluation Method of the Bituminous Pavement Segregation. J. Hunan Univ. (Nat. Sci.) 2016, 43, 129-135.

42. Peng, B.; Cai, C.; Hu, R. Energy consumption and carbon emission evaluation of expressway asphalt pavement. J. Chang. Univ. Nat. Sci. Ed. 2016, 36, 8-15.

43. Quan, H. Research and Implementation of Online Evaluation System for Asphalt Pavement Maintenance Quality. Master's Thesis, Southeast University, Nanjing, China, 2018.

44. Seo, Y. Development and implementation of Korea's first Percent within Limit (PWL) specification for road pavements. KSCE J. Civ. Eng. 2010, 14, 353-361. [CrossRef]

45. Haider, S.W.; Musunuru, G.; Chatti, K. In Effect of Sample Size and Methods on Percent within Limits for Quality Control and Assurance. In Proceedings of the International Conference on Highway Pavements and Airfield Technology, Philadelphia, PA, USA, 27-30 August 2017; pp. 134-144.

46. Wenyou, F.; Long, D. Pavement evaluation with AHP based on expert's assessment. In Proceedings of the 2015 23rd International Conference on Geoinformatics, Wuhan, China, 19-21 June 2015; pp. 1-3.

47. Singh, P.K.; Sarkar, P. A framework based on fuzzy AHP-TOPSIS for prioritizing solutions to overcome the barriers in the implementation of ecodesign practices in SMEs. Int. J. Sustain. Dev. World Ecol. 2019, 26, 506-521. [CrossRef]

48. Cao, W.; Wang, A.; Yu, D.; Liu, S.; Hou, W. Establishment and implementation of an asphalt pavement recycling decision system based on the analytic hierarchy process. Resour. Conserv. Recycl. 2019, 149, 738-749. [CrossRef]

49. Li, H.; Huang, J.; Hu, Y.; Wang, S.; Liu, J.; Yang, L. A new TMY generation method based on the entropy-based TOPSIS theory for different climatic zones in China. Energy 2021, 231, 120723. [CrossRef] 
50. Chen, C.-H. A Novel Multi-Criteria Decision-Making Model for Building Material Supplier Selection Based on Entropy-AHP Weighted TOPSIS. Entropy 2020, 22, 259. [CrossRef]

51. Gelis, K.; Akyurek, E.F. Entropy generation of different panel radiator types: Design of experiments using response surface methodology (RSM). J. Build. Eng. 2021, 41, 102369. [CrossRef]

52. Jiang, Y.; Fang, M.; Liu, Z.; Wang, W. Comprehensive Evaluation of Power Quality Based on an Improved TOPSIS Method Considering the Correlation between Indices. Appl. Sci. 2019, 9, 3603. [CrossRef]

53. Zhu, S.; Wang, Y.; Zheng, J.; Wang, S. RBF Neural Network-Based Frequency Band Prediction for Future Frequency Hopping Communications. Wirel. Commun. Mob. Comput. 2021, 2021, 1-13. [CrossRef]

54. Moradi, M.; Khaleghi, M.; Salimi, J.; Farhangi, V.; Ramezanianpour, A. Predicting the compressive strength of concrete containing metakaolin with different properties using ANN. Measurement 2021, 183, 109790. [CrossRef]

55. Moradi, M.; Daneshvar, K.; Ghazi-Nader, D.; Hajiloo, H. The prediction of fire performance of concrete-filled steel tubes (CFST) using artificial neural network. Thin Walled Struct. 2021, 161, 107499. [CrossRef]

56. Gholampour, F.; Hesameddini, E.; Taleei, A. A stable RBF partition of unity local method for elliptic interface problems in two dimensions. Eng. Anal. Bound. Elem. 2021, 123, 220-232. [CrossRef]

57. Li, Q.; Xiong, Q.; Ji, S.; Yu, Y.; Wu, C.; Yi, H. A method for mixed data classification base on RBF-ELM network. Neurocomputing 2021, 431, 7-22. [CrossRef]

58. Wu, N.-J. Predicting the Compressive Strength of Concrete Using an RBF-ANN Model. Appl. Sci. 2021, 11, 6382. [CrossRef]

59. Мa, C.; Yao, C.; Song, E.-Z.; Ding, S.-L. Prediction and optimization of dual-fuel marine engine emissions and performance using combined ANN with PSO algorithms. Int. J. Engine Res. 2021, 2021, 1468087421990476. [CrossRef]

60. Aziz, N.A.A.; Ibrahim, Z.; Mubin, M.; Nawawi, S.W.; Mohamad, M.S. Improving particle swarm optimization via adaptive switching asynchronous-synchronous update. Appl. Soft Comput. 2018, 72, 298-311. [CrossRef]

61. Ab Aziz, M.F.; A Mostafa, S.; Foozy, C.F.M.; Mohammed, M.A.; Elhoseny, M.; Abualkishik, A.Z. Integrating Elman recurrent neural network with particle swarm optimization algorithms for an improved hybrid training of multidisciplinary datasets. Expert Syst. Appl. 2021, 183, 115441. [CrossRef]

62. Bangyal, W.H.; Hameed, A.; Alosaimi, W.; Alyami, H. A New Initialization Approach in Particle Swarm Optimization for Global Optimization Problems. Comput. Intell. Neurosci. 2021, 2021, 6628889. [CrossRef]

63. Chen, X.; Tianfield, H.; Du, W. Bee-foraging learning particle swarm optimization. Appl. Soft Comput. 2021, 102, 107134. [CrossRef]

64. Wu, X.; Yang, Y.; Han, S.; Zhao, Z.; Fang, P.; Gao, Q. Multi-objective optimization method for nuclear reactor radiation shielding design based on PSO algorithm. Ann. Nucl. Energy 2021, 160, 108404. [CrossRef]

65. Zhu, W.; Rad, H.N.; Hasanipanah, M. A chaos recurrent ANFIS optimized by PSO to predict ground vibration generated in rock blasting. Appl. Soft Comput. 2021, 108, 107434. [CrossRef] 